\title{
Osteoporotic Fractures of Thoracolumbar Spine with Neurodeficit: Radiological Instability Scoring and Minimally Invasive Stabilization
}

\author{
Abhijit Pawar ${ }^{1}$, Bharat Patel $^{2}$, Raghavendra Thete ${ }^{1}$, Mihir Bapat ${ }^{2}$ \\ ${ }^{1}$ Center for Bone and Joint, Kokilaben Dhirubhai Ambani Hospital, Mumbai, India \\ ${ }^{2}$ Spine Department, Nanavati Super speciality Hospital, Mumbai, India
}

Received: December 16, 2020

Revised: May 15, 2021

Accepted: June 27, 2021

Corresponding Author:

Abhijit Pawar, MS

Center for Bone and Joint,

Kokilaben Dhirubhai Ambani

Hospital, Rao Saheb, Achutrao

Patwardhan Marg, Four Bungalows,

Andheri West, Mumbai,

Maharashtra 400053, India

Tel: +91-7387080391

Fax: $+91-2243366777$

E-mail:drabhijitpawar@gmail.com
Objective: Identify unstable osteoporotic fractures with neurological impairment with a radiological instability score and treat them with minimally invasive percutaneous stabilization and vertebroplasty.

Methods: Thirty patients who had osteoporotic vertebral fractures with worsening back pain and neurologic impairment were included in the study. Charlson comorbidity index was used to assess the medical risk for a more extensive surgery. MRI, CT scan and plain radiographs of these patients were evaluated and seven spine instability signs were identified. A score of one was given for presence of one of these risk factors. These patients underwent minimally invasive percutaneous stabilization and vertebroplasty with or without decompression. Pre and post operative ASIA score, VAS scores were recorded. Cobbs angle, and anterior vertebral body height was recorded pre-operative and during each follow up.

Results: There were 11 men and 19 women with a mean age of 71 years (range, 61-89). Sixteen patients had ASIA D, 10 had ASIA C and 4 had ASIA B. All of these patients had an instability score of $\geq 3$. All these patients neurologically recovered, the VAS score for back pain significantly improved, and the spine was stable at one year follow up. Two patient required revision and extension of stabilization due to loosing of pedicle screws and recurrent instability.

Conclusion: Monitoring of spinal instability is essential in osteoporotic vertebral fractures. Presence of three or more instability signs is associated with worsening neurological outcome. These unstable fractures with neurologic impairment can be effectively treated with minimally invasive stabilization and vertebroplasty.

Key Words: Osteoporosis, Vertebral fractures, Instability, Percutaneous stabilization, Verterbroplasty

\section{INTRODUCTION}

Most of the osteoporotic vertebral fractures heal well with conservative management with rest and bracing [1]. However in some patients the fracture healing is impaired which leads to progressive vertebral collapse, fracture non union and spinal cord compression. These fractures if not treated aggressively will lead to significant neurologic deficit and non-ambulatory

Copyright (C) 2021 Korean Minimally Invasive Spine Surgery Society

This is an Open Access article distributed under the terms of the Creative Commons Attribution Non-Commercial License (http://creativecommons.org/licenses/by-nc/4.0/) which permits unrestricted non-commercial use, distribution, and reproduction in any medium, provided the original work is properly cited. 
status [2-4]. Several mechanical factors come into consideration that eventually leads to impingement of neural structures causing devastating neurological compromise [5-7]. Identifying the risk factors for progression at presentation is important. The surgical options in these patients with neurological deficits include vertebral column resection (anterior/posterior) and stabilization. Charlson comorbidity index has shown these patients with advanced age are at risk of prolonged hospital stay and postoperative morbidity with an extensive surgical procedure [8]. Vertebroplasty has shown encouraging results in painful osteoporotic vertebral fractures but has limited role in patients with neurologic deficit.

The purpose of this study is to evaluate the instability signs of osteoporotic compression fractures with neurodeficit and quantify them as an instability score. We also evaluated the efficacy of minimally invasive stabilization and vertebroplasty in these patients.

\section{MATERALS AND METHODS}

Between January 2016 and December 2019, thirty patients with thoracolumbar osteoporotic fractures with neurodeficit who underwent minimally invasive percutaneous stabilization (MIPS) combined with percutaneous vertebroplasty (PVP) with or without localized midline decompression. Electronic medical records of these patients were evaluated after approval from the ethical committee (IRB No: KDA01276). Charlson comorbidity index was used to assess the medical risk for a more extensive surgery. All patients were evaluated by computed tomography (CT), magnetic resonance imaging (MRI) and plain radiographs to determine the morphology of the fracture.

Table 1. Patient demographics and clinical data

\begin{tabular}{|c|c|c|c|c|c|c|c|c|}
\hline Sr. No. & Age (yr) & Sex & Charlson comorbity index & Level & ASIA grade Preop & ASIA grade at $3 \mathrm{mo}$ & Preop VAS for back pain & Postop VAS score \\
\hline 1 & 70 & $F$ & 4 & \#D10 & C & $E$ & 9 & 3 \\
\hline 2 & 84 & $F$ & 5 & \#D12 & C & $E$ & 8 & 3 \\
\hline 3 & 61 & $F$ & 3 & \#D12 & $D$ & $E$ & 8 & 2 \\
\hline 4 & 78 & $F$ & 4 & \#D12 & C & D & 7 & 2 \\
\hline 5 & 77 & $\mathrm{~F}$ & 5 & \#D12 & $D$ & $E$ & 8 & 2 \\
\hline 6 & 72 & $\mathrm{~F}$ & 5 & \#D12 & C & $E$ & 8 & 4 \\
\hline 7 & 61 & $\mathrm{~F}$ & 2 & \#D9 & $D$ & $E$ & 9 & 2 \\
\hline 8 & 62 & $\mathrm{~F}$ & 2 & \#L1 & D & $E$ & 8 & 3 \\
\hline 9 & 63 & $\mathrm{~F}$ & 2 & \#L1 & D & $E$ & 9 & 3 \\
\hline 10 & 64 & $\mathrm{~F}$ & 2 & \#L2 & D & $E$ & 8 & 1 \\
\hline 11 & 65 & $\mathrm{~F}$ & 2 & \#D12 & C & $E$ & 8 & 5 \\
\hline 12 & 80 & $\mathrm{M}$ & 4 & \#D12 & D & $E$ & 7 & 3 \\
\hline 13 & 81 & $\mathrm{M}$ & 3 & \#D12 & C & $E$ & 9 & 0 \\
\hline 14 & 74 & $\mathrm{M}$ & 3 & \#L1 & $D$ & $E$ & 9 & 1 \\
\hline 15 & 75 & $F$ & 4 & \#L1 & C & $E$ & 10 & 4 \\
\hline 16 & 75 & $\mathrm{M}$ & 4 & $\#\llcorner 4$ & C & $E$ & 10 & 1 \\
\hline 17 & 74 & $\mathrm{~F}$ & 4 & \#L2 & B & D & 10 & 4 \\
\hline 18 & 81 & $\mathrm{M}$ & 5 & \#L1 & D & $E$ & 9 & 2 \\
\hline 19 & 68 & $F$ & 4 & \#L2 & D & $E$ & 10 & 0 \\
\hline 20 & 74 & $\mathrm{~F}$ & 4 & \#D12 & D & $E$ & 9 & 0 \\
\hline 21 & 67 & $\mathrm{~F}$ & 3 & \#D12 & B & D & 10 & 4 \\
\hline 22 & 67 & $\mathrm{~F}$ & 2 & \#L1 & C & $E$ & 10 & 1 \\
\hline 23 & 75 & $M$ & 4 & \#L1 & $D$ & $E$ & 10 & 0 \\
\hline 24 & 75 & $\mathrm{~F}$ & 4 & \#L1 & B & D & 9 & 2 \\
\hline 25 & 82 & $M$ & 5 & \#D12 & C & $E$ & 9 & 0 \\
\hline 26 & 65 & $M$ & 2 & \#L1 & B & D & 9 & 3 \\
\hline 27 & 67 & $\mathrm{~F}$ & 3 & \#L2 & D & $E$ & 10 & 0 \\
\hline 28 & 69 & $\mathrm{M}$ & 4 & \#L3 & $D$ & $E$ & 10 & 3 \\
\hline 29 & 66 & $M$ & 3 & \#L1 & $D$ & $\mathrm{E}$ & 10 & 0 \\
\hline 30 & 68 & $M$ & 3 & \#L1 & $D$ & $E$ & 10 & 0 \\
\hline
\end{tabular}




\section{Patient Demographics and Clinical Data (Table 1)}

Clinical evaluation was done using VAS (visual analogue scale), and ASIA score done pre operatively, immediate post operatively, at 3 and 12 months. All patients were non ambulatory due to severe pain and neurologic impairment. They had bone mineral density (BMD) of more than 2.5 SD below the young adult mean ( -2.5 SD or lower). Patients less than 65 years in age, patients with pathological fracture, osteomyelitis and patients with normal $\mathrm{T}$ score for BMD were excluded from the study.

\section{Pre-operative Risk Factor Scoring}

Extensive literature search was done to find out factors that predict worsening in osteoporotic fractures. Authors found seven important factors that need to be observed in these patients. All patients were evaluated before the surgery by plain radiographs, CT and MRI to determine the presence of these risk factors. A score of 1 was given for the presence of each of these parameters. After surgery the patients had serial radiographs to assess alignment, screw loosening and implant failure.

\section{1) Incomplete Burst Fractures}

Patients who had middle column involvement at presentation. These patients have a tendency to progress to non union and collapse of the vertebral body leading to spinal canal compression $[3,7,9,10]$.

\section{2) Vacuum Sign}

The condition of affected vertebrae was evaluated for the intravertebral air or intervertebral fluid or both. Intraverterbal fluid was area of hypointensity on the T1 weighted images and hyperintensity on T2 weighted images on MRI. Intervertebral air was area of hypointensity on $\mathrm{T} 1$ and $\mathrm{T} 2$ weighted images [11-14].

\section{3) Local Kyphosis}

Was calculated on the Cobb angle between the cranial end plate of vertebra just proximal to the fracture and the caudal endplate of the vertebra just distal to the fractured vertebrae on lateral plain X-ray films $[3,7,15]$.

\section{4) Retropulsion/Spinal Canal Encroachment}

Migration of the posterior vertebral elements into the spinal canal was categorized as retropulsion of the vertebral body $[2,3,9]$. Retropulsion further progressed to spinal canal en- croachment. This was measured as ratio of the sagittal diameter of the bony fragments into the spinal canal to the sagittal diameter of the spinal canal at one level proximal to the fractured vertebrae. Greater than $25 \%$ was regarded as significant compression leading varying degree of neurologic deficits $[3,6]$.

\section{5) Posterior Ligament Injury}

Involvement of the posterior interspinous ligaments at initial injury or gradual failure of the posterior ligaments with progressive kyphosis was regarded as tri column involvement. Injury to these structures can lead to progession of deformity [9]. Posterior ligamentous injury was assessed from CT as widening of spinous processes or on MRI from edema of the interspinous ligament.

6) Multiple Wedge Compression Fractures

More than one compression fractures was included as a risk factor. This results in increase in deformity with worsening neurology.

7) Anterior Vertebral Height Loss $>50 \%$

The anterior vertebral height of the fractured vertebrae was compared to the normal vertebrae above. This leads to worsening sagittal profile. The height restored after surgery was also measured [16].

The spinal instability was calculated by adding these seven radiographic parameters with a score of one given for presence of each risk sign. These patients had 3 or more risk factors seen radiologically at presentation. Hence authors of this study considered a score of 3 or more as an unstable for this group of patients. Total score was divided into two categories of stability: stable (0-2) and unstable ( $\geq 3$ ) (Table 2).

\section{Surgical Technique (Figure 1)}

Patient is postioned prone on bolsters. This leads to partial

Table 2. Risk factors for osteoporotic vertebral fractures

\begin{tabular}{llc}
\hline Serial No. & \multicolumn{1}{c}{ Spine at risk sign } & Score \\
\hline 1 & $\begin{array}{c}\text { Incomplete burst fractures (middle column in- } \\
\text { volvement)I }\end{array}$ & 1 \\
2 & Vacuum sign & 1 \\
3 & Local kyphosis of more than 20 degrees & 1 \\
4 & $\begin{array}{l}\text { Retropulsion/spinal canal encroachment of more } \\
\text { than 25\% }\end{array}$ & 1 \\
5 & Posterior ligament injury & 1 \\
6 & Multiple wedge compression fractures & 1 \\
7 & Anterior vertebral height loss of $>50 \%$ & 1 \\
\hline
\end{tabular}



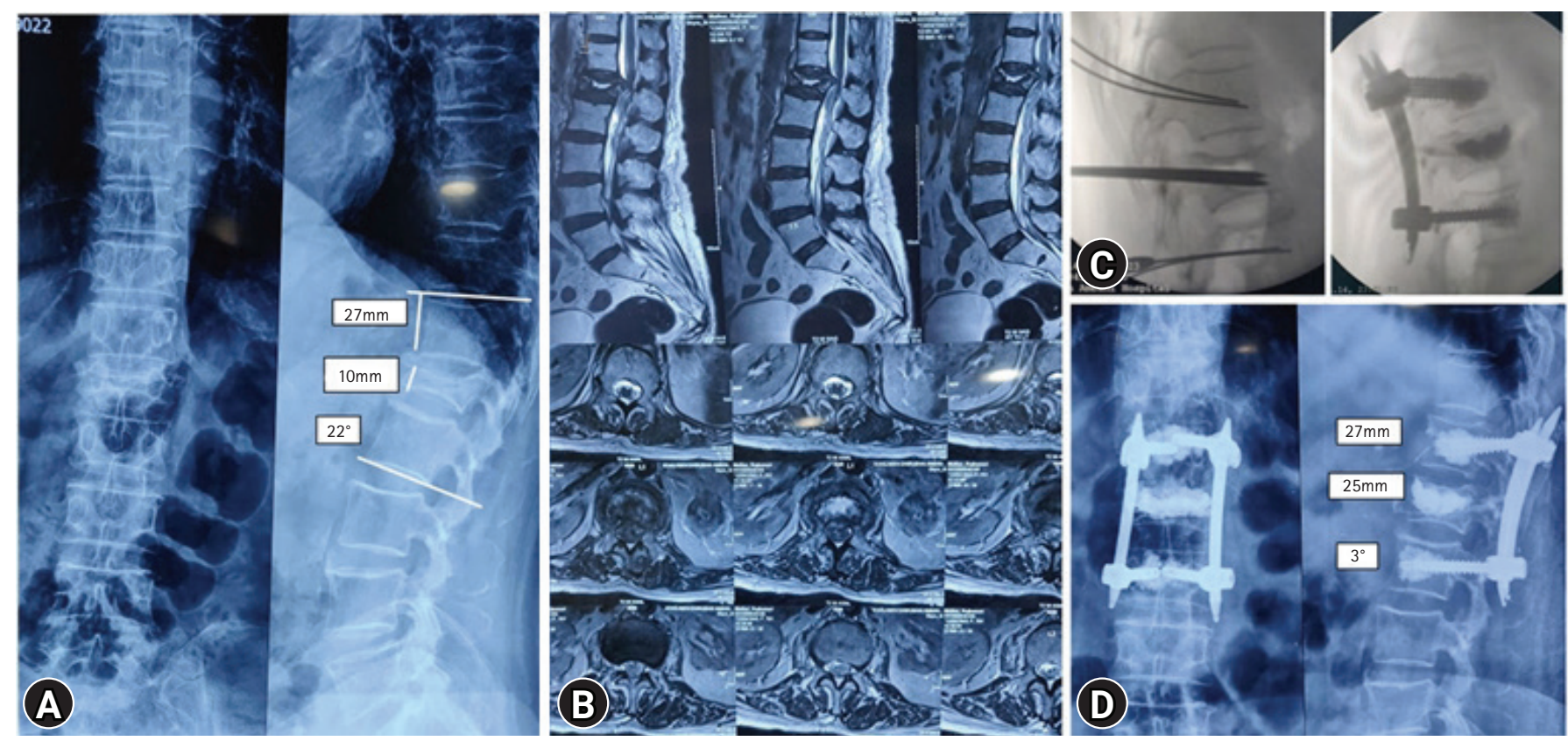

Figure 1. A 78-year-old wheelchair bound female with ASIA C neurology. (A, B) Vaccum sign+, local kyphosis of $24^{\circ}$, anterior vertebral height loss of $>50 \%$, retropulsion and spinal canal encroachment 7>25\% (instability score 4). (C) Guide wires and biportal vetebroplasty needles placed. (D) Vertebroplasty and minimally invasive stabilization with cement augmented percutaneous pedicular screws.

correction of kyphosis and restoration of anterior vertebral height. At first the pedicles of the affected segment were identified and skin was marked. The entry points for the percutaneous guide wires were made based on the $\mathrm{C}$ arm. Jamshedi needles were passed in to the pedicle after the position was confirmed on the image intensifier. Percutaneous screws were passed one level above and one level below the fracture over guide wire. In patients with higher angle of kyphosis screws were placed 2 levels above and below the fracture. In patients with severe osteoporosis they were augmented with bone cement. Two vertebroplasty needles were also passed in the fractured vertebra (Biportal Vertebroplasty). Position confirmed and about 4-6 $\mathrm{mL}$ of vertebroplasty cement was injected under fluoroscopy until cement reached the posterior $1 / 3$ rd of the vertebral body. Once the position of the cement was confirmed midline decompression was done at the level of retropulsion if necessary. In the current series midline decompression was done in 6 patients who retropulsion and canal encroachment of $>50 \%$. Midline incision was taken, paraspinal muscles retracted to expose the lamina. Partial laminectomy and decompression was done. When we stabilize and correct the kyphosis with rods the retropulsion decreases resulting in indirect decompression. The patients were mobilized on post-operative day one with braces in presence of physiotherapist.

\section{Clinical and Radiological Evaluation (Table 3)}

The clinical and radiological evaluation were done pre operative, immediate post operative, 3 months and 1 year after surgery. The severity of the neurologic deficits was assessed using ASIA (American spinal injury Association) impairment scale. The pain intensity was recorded using the visual analogue scale (VAS). Focal kyphosis, vertebral body height and hardware loosening or implant failure were assessed at follow up.

\section{Statistical Analysis}

Comparison of pre and post-operative measurements was performed using t-test for independent samples. Statistically significant differences were defined at a $95 \%$ confidence level. The values were given as mean \pm SD. The SPSS software was used for statistical evaluation.

\section{RESULTS}

\section{Clinical Outcome and Radiological Outcome (Figure 2, 3)}

Electronic medical records of a total of 30 patients were evaluated clinically and radiologically. The most common level 
Table 3. Radiological parameters in these patients

\begin{tabular}{|c|c|c|c|c|c|c|c|c|}
\hline Sr No. & AOK Preop & AOK Postop & Incomplete burst \# & VS & CE in $\%$ & PLC injury & Multiple comp \# & $>50 \%$ VBH loss \\
\hline 1 & 15 & 5 & 0 & 1 & 25 & 0 & 0 & 1 \\
\hline 2 & 10 & 18 & 1 & 1 & 30 & 1 & 1 & 0 \\
\hline 3 & 10 & 10 & 1 & 1 & 15 & 0 & 1 & 1 \\
\hline 4 & 20 & 15 & 0 & 1 & 40 & 1 & 0 & 0 \\
\hline 5 & 0 & 16 & 1 & 1 & 30 & 0 & 0 & 1 \\
\hline 6 & $0-5$ & 20 & 1 & 1 & 35 & 0 & 0 & 1 \\
\hline 7 & 20 & 20 & 0 & 1 & 15 & 0 & 0 & 1 \\
\hline 8 & 10 & 0 & 1 & 1 & 15 & 0 & 0 & 1 \\
\hline 9 & 20 & 5 & 0 & 1 & 20 & 0 & 0 & 1 \\
\hline 10 & 20 & 5 & 0 & 1 & 15 & 0 & 0 & 1 \\
\hline 11 & 0 & 0 & 1 & 1 & 35 & 0 & 0 & 0 \\
\hline 12 & 0 & 0 & 1 & 1 & 15 & 0 & 0 & 0 \\
\hline 13 & 10 & 0 & 0 & 1 & 20 & 0 & 0 & 0 \\
\hline 14 & 10 & 0 & 1 & 1 & 25 & 0 & 0 & 0 \\
\hline 15 & 30 & 10 & 1 & 1 & 40 & 1 & 1 & 1 \\
\hline 16 & 10 & 0 & 1 & 0 & 30 & 1 & 0 & 1 \\
\hline 17 & 20 & 10 & 0 & 1 & 40 & 1 & 1 & 1 \\
\hline 18 & 20 & 10 & 0 & 1 & 30 & 1 & 0 & 1 \\
\hline 19 & 15 & 0 & 0 & 1 & 10 & 1 & 0 & 1 \\
\hline 20 & 30 & 10 & 0 & 1 & 30 & 0 & 1 & 1 \\
\hline 21 & 30 & 25 & 0 & 1 & 30 & 0 & 1 & 1 \\
\hline 22 & 26 & 20 & 0 & 1 & 30 & 0 & 1 & 1 \\
\hline 23 & 0 & 0 & 1 & 0 & 20 & 1 & 0 & 0 \\
\hline 24 & 30 & 10 & 0 & 1 & 40 & 0 & 1 & 0 \\
\hline 25 & 30 & 10 & 0 & 1 & 30 & 0 & 1 & 0 \\
\hline 26 & 30 & 10 & 0 & 1 & 40 & 0 & 1 & 0 \\
\hline 27 & 15 & 0 & 0 & 1 & 10 & 1 & 0 & 1 \\
\hline 28 & 15 & 0 & 1 & 1 & 25 & 0 & 0 & 1 \\
\hline 29 & 0 & 0 & 1 & 0 & 20 & 1 & 0 & 1 \\
\hline 30 & 10 & 0 & 1 & 0 & 25 & 1 & 0 & 1 \\
\hline
\end{tabular}

AOK: angle of kyphosis, VS: vacuum sign, CE: canal encroachment, \#: fracture, PLC: posterior ligament complex, VBH: vertebral body height.

involved was D12 followed by L1. These patients had failed average conservative trial of 9 weeks (range, $8-14$ weeks) before they presented to us with neurodeficit. There were 11 men and 19 women with a mean age of 71 years (range, $61-89$ years). The average Charlson comorbidity index was 4 (range, 2-5). The average duration of surgery was 130 minutes (110- 180 minutes) and the mean blood loss was $80 \mathrm{~mL}$ (range, $60-300 \mathrm{~mL}$ ). Single level (one above and one below) minimally invasive stabilization was done in 26 patients while two levels ( 2 above and 2 below) were done in 4 patients with higher degree of kyphosis. In 6 patients cement augmented pedicle screws were used to augment the stabilization. The mean follow up was 28 months (range, 20-36 months) and the average hospital stay was 4 days (3-8 days). There was no perioperative complications, infection or death. The VAS significantly dropped from average pre-oper- ative 9 (range, 7-10) to 2 (range, 1-4) immediately after surgery and 1 (range $0-1)$ at 1 year follow up $(\mathrm{p}<0.001)$. Burst fracture with middle column involvement was seen in 14 patients. Vacuum sign was seen in 26 patients. Retropulsion and more than $25 \%$ spinal canal encroachment was seen in 26 patients. The average local angle of kyphosis was $18^{\circ}$ pre operatively (range, $12^{\circ}-30^{\circ}$ ) which decreased to $6^{\circ}$ post operatively (range, $\left.0^{\circ}-14^{\circ}\right)(\mathrm{p}<0.001)$. Single level vertebral collapse was seen in 25 patients, 3 patients had 2 level vertebral collapse and 2 patients has 3 level vertebral collapse. Injury to posterior spinal ligaments was seen in 14 patients. Nine patients had posterior ligament injury at the time of fall. Posterior column injury as a result of stretch injury to posterior ligamentous structures due to progressive increase in kyphosis was seen in 5 patients. Greater than $50 \%$ vertebral height loss was seen in 20 patients. 

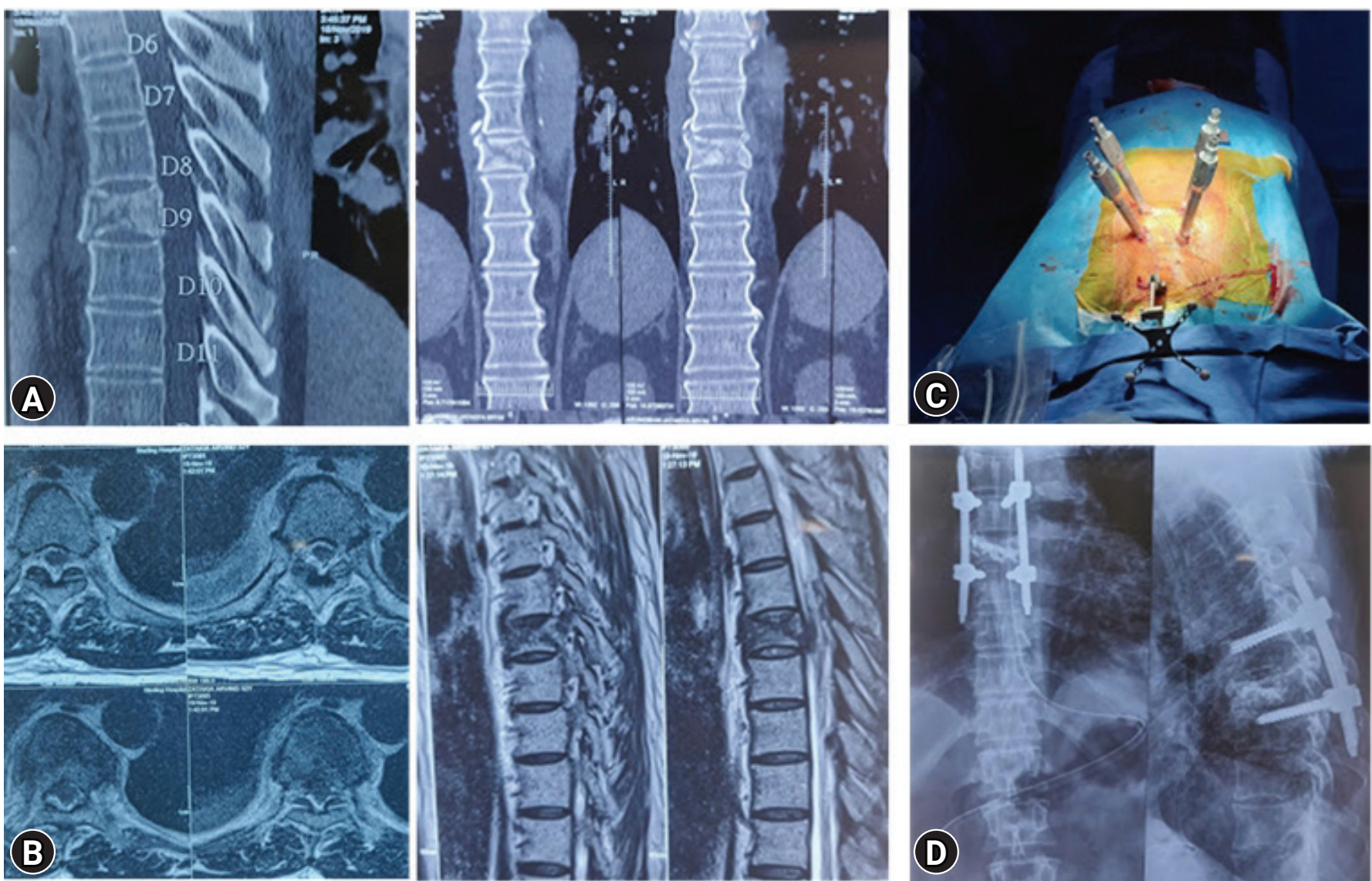

Figure 2. A 68-year-old male ASIA D Incomplete Burst \#. (A, B) Incomplete burst \# with retropulsion and posterior ligamentous injury (instability score 3). (C, D) Navigation guided MIS stabilization and D9 vertebroplasty.

The average pre operative anterior vertebral body height was $12 \mathrm{~mm}$ (range, 5-20 $\mathrm{mm}$ ) which increased to average post operative anterior vertebral height of $20 \mathrm{~mm}$ (range, 12-27 mm) $(\mathrm{p}<0.001)$. In the current series, a varied neurological deficit at presentation was seen. Sixteen patients had ASIA D, 10 had ASIA C and 4 had ASIA B. Improvement in neurological status was observed in all these patients. At 3 months follow up 4 patients improved from ASIA B to ASIA D, 10 improved from ASIA $C$ to ASIA $E$ and 16 patients improved from ASIA D improved to ASIA E. There was loosing of hardware seen in 2 patients at 1 year follow up which required revision to longer instrumentation. The was some loss of correction at one year follow up with angle of kyphosis increasing from average $6^{\circ}$ to $12^{\circ}$ (range, $0^{\circ}-16^{\circ}$ )at one year follow up.

\section{DISCUSSION}

Osteoporotic vertebral fractures lead to debilitating pain necessitating prolonged bed rest and increase in morbidity and mortality $[1,2]$. From different studies in literature the risk factors leading to progression and neurologic impairment were evaluated. According to Denis [9] damage to all three columns has a greater risk of pseudoarthrosis and progression of vertebral collapse. It is important to identify middle column involvement at presentation in this group of patients. Fourteen patients had middle column involvement (incomplete burst fractures) in this series. Since they were incomplete burst without retropulsion they were initially treated conservatively. There is enough evidence to suggest that involvement of middle column and posterior wall of vertebral body increases the risk of non union and progression $[3,7,10]$. These patients need a close watch when conservative treatment is recommended. Intervertebral vacuum cleft represents a radiological sign of avascular necrosis of vertebral body will lead to pseudoarthrosis and further vertebral collapse [11-14]. This vacuum sign was present in 26 patients suggestive of spinal instability. Hoshino et al. [3] observed that severity of neurological deficit was related to angular instability of more than $15^{\circ}$ and occupation of spinal canal with retropulsed fragments. In the current study the average preoperative angle of kyphosis was $18^{\circ}$ which was 

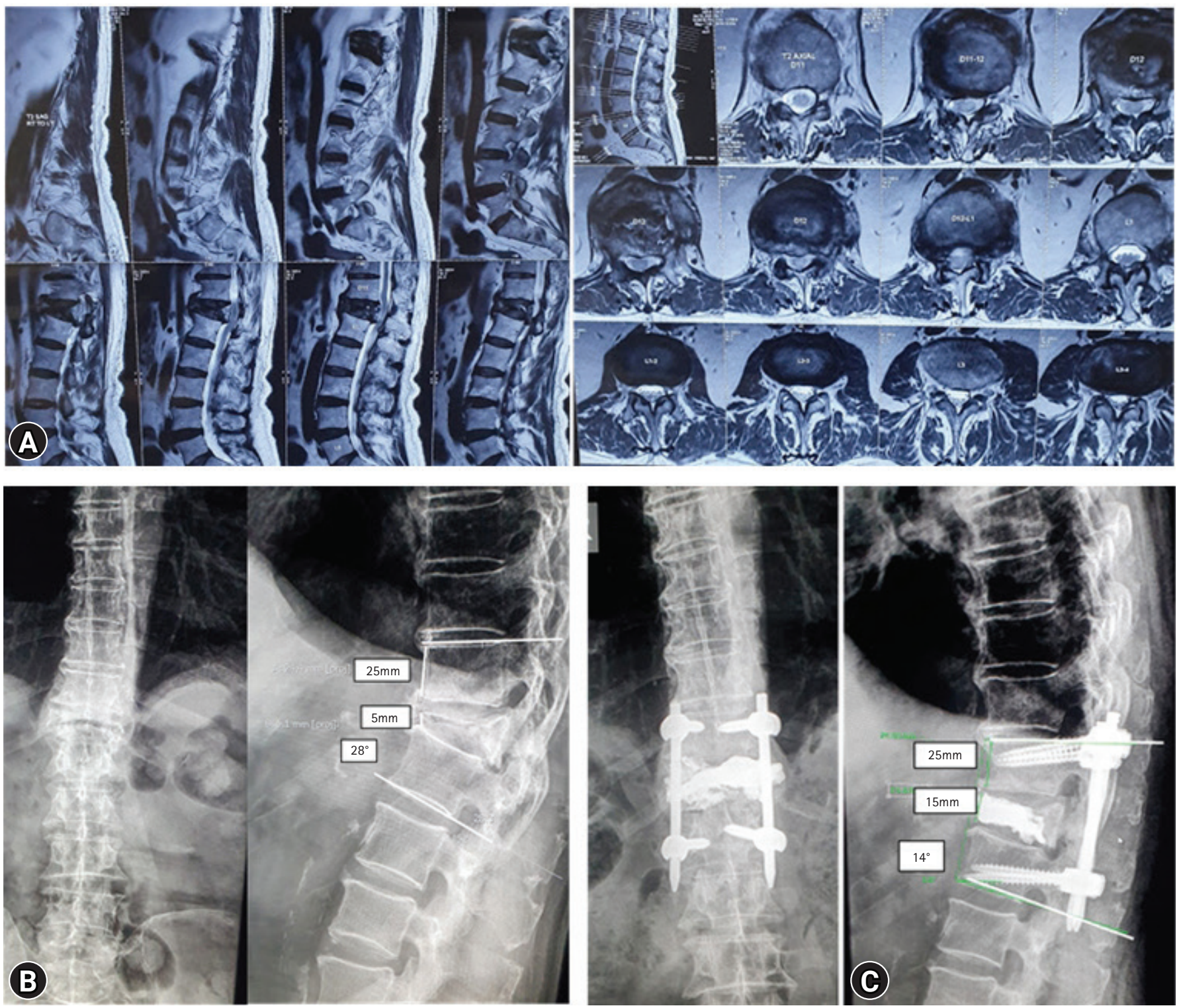

Figure 3. An 82-year-old male with ASIA D neurology. (A, B) Imaging s/o Figure 1 and 2: Vaccum sign+, local kyphosis of 30 anterior vertebral height loss of $>50 \%$, retropulsion and spinal canal encroachment $>25 \%$ (instability score 4). (C) MIS stabilization and vertebroplasty.

corrected to $6^{\circ}(\mathrm{p}<0.001)$. Anterior vertebral height loss was measured as compared to above normal vertebrae. The AVH increased from a average preoperative value of 12 to $20 \mathrm{~mm}$ postoperatively $(\mathrm{p}<0.001)$. Correction of kyphosis and fairly good restoration of $\mathrm{AVH}$ resulted in indirect decompression and vertebroplasty lead to anterior column support. Baba et al. [2] concluded that the dynamic instability with hyper mobility at fractured level leads to gradual retropulsion of bony fragment into spinal canal which causes neurological impairment. Retropulsion of posterior vertebral elements was seen in 26 patients. Progression of retropulsion leads to spinal canal encroachment
[3,6,9]. Greater than $25 \%$ spinal canal encroachment was seen in 20 patients in the current series. If the canal encroachment was between $25 \%$ to $50 \%$ authors of this study recommend only MIPS with VP. If the canal encroachment was greater than $50 \%$ then midline decompression was necessary. Bilateral decompression with unilateral laminotomy can preserve the midline structures however in these patients authors felt that midline approach would achieve a better decompression. We also evaluated whether there was a involvement of posterior elements and for multiple level wedge compression fractures $[5,6,9,15]$. Fourteen patients had posterior ligament injury in this study. 
Nine patients had posterior ligament injury at presentation as seen on MRI (edema of interspinous ligaments) or CT (widening of interspinous distance). Posterior column injury as a result of stretch injury to posterior ligamentous structures due to progressive increase in kyphosis was seen in other five patients. It is important for clinician to watch for posterior ligament injury in these patients at presentation and at follow up. This would also lead to progression of deformity and worsening of neurology. Multiple wedge compression fracture was another factor present in 4 patients. We observed that most of the instability factors are related to each other. Incomplete burst would result in retropulsion and non union and gradual increase in kyphosis. This progressed to stretch injury to posterior elements and multiple fractures. Hence it is necessary to break this cycle of risk factors progression. A score of 1 was given for the presence of each of these parameters. The spinal instability was calculated by adding these seven radiographic parameters. All of these patients had 3 or more risk factors seen on radiology at presentation. So we concluded that 3 or more score as an unstable score for these patients. Total score was divided into two categories of stability: stable (0-2) and unstable $(\geq 3)$. The patients with instability score of 2 or less can be treated conservatively with medication and bracing. This scoring of instability can help surgeons to predict conservative treatment failure and need for surgical treatment.

As in case of traumatic vertebral fractures in young patients, where treatment is been well established, strategies are unclear for vertebral fractures in elderly population $[5,6]$. Patients in this study had failed conservative treatment with braces and medications or had gradually progressed despite appropriate precautions and treatment. These patients had a BMD of $<2.5 \mathrm{SD}$ along with osteoporotic fracture hence they were categorized as severe osteoporosis [17].These patients were non ambulatory due to severe pain and neurologic impairment. Sixteen patients were ASIA D, 10 patients ASIA C and 4 patients ASIA $B$ at presentation. As most of these patients had significant canal encroachment, angular kyphosis, instability of middle and posterior column, the surgery of vertebral column resection and stabilization would be one option in treating these patients [1,18-20]. They also had 2 or more medical comorbidities like diabetes, history or stroke, myocardial infarction or dementia. The average Charlson comorbidity index was 4 suggesting that they were at risk of prolonged hospital stay and post operative morbidity if extensive anteroposterior decompression was attempted [8]. Considering the age, and morbidity of the procedure, we decided to treat them with a minimally invasive stabilization and anterior column support by vertebroplasty. In this study the fracture was reduced partially by placing the patient prone on bolsters and partially by proper distraction applied between 2 screws as necessary before vertebroplasty. Anterior column support was provided by vertebroplasty cement [1]. Hydroxyappatite vertebroplasty cement was used in all patients. In 6 patients, decompression was done using mini-midline incision however reconstruction of the anterior spine column with cage was not attempted. This surgery was tolerated well in this elderly population $[16,20,21]$. Single level stabilization was done when the kyphosis was less than $30^{\circ}$ while 2 levels above and below stabilization was necessary in 4 patients with kyphosis greater than $30^{\circ}$. Two patients had loosing of the hardware at year follow up and needed revision to long segment stabilization. This could be a result of lack of fusion as no bone graft was used in anterior or posterior column. In the present study, VAS score improved significantly after surgery $(\mathrm{p}<0.001)$. Improvement in paraplegia was observed after surgery in all of these patients. Patients with ASIA B at presentation reached ASIA D at 1 year follow up and the rest reached ASIA scale E.

The study is not without limitations. The study has small sample size and is retrospective in nature. The entire scoring system was based on individuals who received a surgical intervention. A prospective study to see the natural progression of the osteoporotic fractures would answer these questions regarding the instability more effectively. It would be ideal to identify these risk factors at the onset and prevent the progression of instability. The scoring system needs to be validated. Through this study the authors wish to highlight the instability factors in osteoporotic vertebral fractures which can potentially risk progression and worsening of neurology.

\section{CONCLUSION}

The prediction of late neurologic deficit, progression of kyphotic deformity in vertebral compression fractures is difficult.

Prolonged monitoring is necessary in vertebral compression fractures. Minimally invasive stabilization with or without local decompression and vertberoplasty is well tolerated in the elderly population with encouraging results. We concluded that patients with osteoporotic vertebral fractures who had 3 or more risk factors were at a risk of failure of conservative treatment. If the prognosis can be predicted on the early stage more aggressive and better treatment options can be considered to prevent neurological involvement. 


\section{CONFLICT OF INTEREST}

No potential conflict of interest relevant to this article.

\section{REFERENCES}

1. Blattert TR, Schnake KJ, Gonschorek O, Gercek E, Hartmann F, Katscher S, et al; Spine Section of the German Society for Orthopaedics and Trauma. Nonsurgical and surgical management of osteoporotic vertebral body fractures: recommendations of the Spine Section of the German Society for Orthopaedics and Trauma (DGOU). Global Spine J 2018;8:50S-55S.

2. Baba H, Maezawa Y, Kamitani K, Furusawa N, Imura S, Tomita K. Osteoporotic vertebral collapse with late neurological complications. Paraplegia 1995;33:281-289.

3. Hoshino M, Nakamura H, Terai H, Tsujio T, Nabeta M, Namikawa T, et al. Factors affecting neurological deficits and intractable back pain in patients with insufficient bone union following osteoporotic vertebral fracture. Eur Spine J 2009;18:1279-1286.

4. Rajasekaran S, Kanna RM, Schnake KJ, Vaccaro AR, Schroeder GD, Sadiqi S, et al. Osteoporotic thoracolumbar fractures-how are they different?-classification and treatment algorithm. J Orthop Trauma 2017;31 Suppl 4:S49-S56.

5. Faciszewski T, Mckiernan F, Jensen R, Kraus K. 4:31 The dynamic mobility of vertebral compression fractures. Spine J 2002;2 Suppl:S96-S97.

6. Goldstein S, Smorgick Y, Mirovsky Y, Anekstein Y, Blecher R, Tal S. Clinical and radiological factors affecting progressive collapse of acute osteoporotic compression spinal fractures. J Clin Neurosci 2016;31:122-126.

7. Sohn JM, Kim KW, Ha KY, Ha NK, Kim YH, Kim JH. Risk factors for the progressive osteoporotic spinal fracture. J Korean Soc Spine Surg 2009;16:153-159.

8. Charlson M, Szatrowski TP, Peterson J, Gold J. Validation of a combined comorbidity index. J Clin Epidemiol 1994;47:12451251.

9. Denis F. Spinal instability as defined by the three-column spine concept in acute spinal trauma. Clin Orthop Relat Res 1984;(189):65-76.

10. Tsujio T, Nakamura H, Terai H, Hoshino M, Namikawa T, Matsumura A, et al. Characteristic radiographic or magnetic resonance images of fresh osteoporotic vertebral fractures predicting potential risk for nonunion: a prospective multicenter study. Spine (Phila Pa 1976) 2011;36:1229-1235.
11. Kumpan W, Salomonowitz E, Seidl G, Wittich GR. The intravertebral vacuum phenomenon. Skeletal Radiol 1986;15:444447.

12. Libicher M, Appelt A, Berger I, Baier M, Meeder PJ, Grafe I, et al. The intravertebral vacuum phenomen as specific sign of osteonecrosis in vertebral compression fractures: results from a radiological and histological study. Eur Radiol 2007;17:2248-2252.

13. Maldague BE, Noel HM, Malghem JJ. The intravertebral vacuum cleft: a sign of ischemic vertebral collapse. Radiology 1978;129:23-29.

14. Murakami H, Kawahara N, Gabata T, Nambu K, Tomita K. Vertebral body osteonecrosis without vertebral collapse. Spine (Phila Pa 1976) 2003;28:E323-E328.

15. Ha KY, Kim YH. Risk factors affecting progressive collapse of acute osteoporotic spinal fractures. Osteoporos Int 2013; 24:1207-1213.

16. Gu Y, Zhang F, Jiang X, Jia L, McGuire R. Minimally invasive pedicle screw fixation combined with percutaneous vertebroplasty in the surgical treatment of thoracolumbar osteoporosis fracture. J Neurosurg Spine 2013;18:634-40.

17. Kanis JA. Assessment of fracture risk and its application to screening for postmenopausal osteoporosis: synopsis of a WHO report. WHO Study Group. Osteoporos Int 1994;4:368381.

18. Katsumi K, Hirano T, Watanabe K, Ohashi M, Yamazaki A, Ito T, et al. Surgical treatment for osteoporotic thoracolumbar vertebral collapse using vertebroplasty with posterior spinal fusion: a prospective multicenter study. Int Orthop 2016;40:2309-2315.

19. Sudo H, Ito M, Kaneda K, Abumi K, Kotani Y, Nagahama K, et al. Anterior decompression and strut graft versus posterior decompression and pedicle screw fixation with vertebroplasty for osteoporotic thoracolumbar vertebral collapse with neurologic deficits. Spine J 2013;13:1726-1732.

20. Uchida K, Nakajima H, Yayama T, Miyazaki T, Hirai T, Kobayashi S, et al. Vertebroplasty-augmented short-segment posterior fixation of osteoporotic vertebral collapse with neurological deficit in the thoracolumbar spine: comparisons with posterior surgery without vertebroplasty and anterior surgery. J Neurosurg Spine 2010;13:612-621.

21. Gu YT, Zhu DH, Liu HF, Zhang F, McGuire R. Minimally invasive pedicle screw fixation combined with percutaneous vertebroplasty for preventing secondary fracture after vertebroplasty. J Orthop Surg Res 2015;10:31. 